\title{
Investor Following And Volatility: A GARCH Approach
}

Amal Aouadi, CRCGM - University of Auvergne, France Mohamed Arouri, EDHEC Business School, France

Frédéric Teulon, Business School, IPAG - Lab, France

\begin{abstract}
In this paper, we aim to investigate whether investor following is a determinant of the stock market volatility. To measure investor following, we use "Google Insights for search" freshly introduced to the financial literature. The latter records the online search traffic for any keyword submitted to Google since 2004. Thanks to an extensive database, we focus precisely on the French stock market unlike previous works, which have focused largely on the US stock market. Notably, our findings support strong significant effects of investor following as measured by online search behavior on the conditional volatility estimated from GARCH (1,1) Market model. Our results are robust to additional tests.
\end{abstract}

Keywords: Investor Following; Online Search; Stock Volatility

\section{INTRODUCTION}

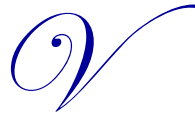

olatility is a key variable in the financial literature. Yet, up to now, its determinants still partially identified [Wei and Zhang (2006) and Fink et al. (2010)]. At least as early as Shiller (1981), numerous studies show that volatility cannot be exclusively explained by changes in fundamentals. The purpose of this paper is to investigate whether investor following with respect to searching, gathering and processing firm news is a determinant of the stock market volatility. For so long already, Merton (1987) introduces that investors prefer stocks they recognize. Thus, according to the investor recognition theory, stocks followed by investors would be more traded than stocks less familiar. Actually, investors are influenced by the information they hold. Consequently, they tend to invest in what they know. Today, given our digitized world in which information travels very fast, this information-based trading can lead investors to trade too speculatively and may influence asset pricing dynamics.

Assessing investor following presents a major difficulty in that there is no direct measure that can illustrate the investor behavior. In this paper, we introduce a new measure of investor following which relies on the intuition behind works on investor attention such as Da et al. (2011) and Vlastakis and Markellos (2012). We take an original approach and proxy firm's investor following on the basis of investors' online search behavior. The latter is exclusively provided by Google Insights for Search with the methodology described in Section 2 [Mondria et al. (2010) and Da et al.(2011)]. Specifically, we use Google French data by focusing for the first time on the French stock market. By using such data, we add further evidence that Google, the most popular internet search engine, has completely revolutionized the diffusion, supply and demand for information by making it less costly and easily available for retail investors. This is certainly the main reason which explains why people rely mostly on search engines to track information on the web.

Google is popular everywhere. Especially in France, Google continues to dominate the list of most used search engines, by a wide margin. Indeed, according to AT Internet, Google is far and away the search engine of choice, preferred by $91 \%$ of the French search users (as of July 2013). Similarly, in December 2012, there are 48 million internet users in France spending on average 26.9 hours/month on the Internet. It seems reasonable to suppose that online search traffic may influence the stock market volatility once it was proven to have an impact on the stock market activity. For instance, an emerging stream of literature suggests that Google search frequency helps 
to improve the stock liquidity. Specifically, Bank et al. (2011) find that higher Google search volume decreases stock illiquidity and leads to higher future returns in the short run. Similarly, Ding and Hou (2012) show that online search is positively associated with the shareholder base and liquidity. More interestingly, a growing strand of literature finds consistent evidence that Google search frequency is strongly linked to the stock volatility. Vlastakis and Markellos (2012) show that information demand, proxied by Google search volume, helps to explain approximately $50 \%$ of variations in the Market Volatility Index (the VIX). Otherwise, using Google searches as a proxy for retail investors' attention, Dimpfl and Jank (2011) find that online search constitutes an additional source of future market volatility. Further, Kita and Wang (2012) argue that volatility in FX markets is driven by investor attention as proxied by Google search volume. In currencies market, Smith (2012) finds that Google searches for some economic keywords such as "economic crisis", "financial crisis" and "recession" has incremental predictive power for the volatility of seven currencies.

It is important to understand how investor following with respect to information-based trading affects the volatility of stock returns. In particular, any investor would want to know what are the determinants of the risk and value of his portfolio, especially in recent times. The advantage of knowing about risk is that we can change our behavior to avoid it. Moreover, volatility plays an important role in pricing options, risk management (e.g., Valueat-Risk), and asset allocation. For instance, volatility is used to construct optimal hedge ratios to trade against risk and to assess the value of that risk.

Our paper complements and extends prior studies in different ways. First, we add further evidence to the power of online search data over a number of financial settings. We also contribute to the existing literature by introducing a new measure of investor following: investors' online search behavior. Previous work on retail investor behavior use passive measures such as trading volume, price limits or media coverage, which does not automatically guarantee that investor is really devoting attention to a particular firm. Second, we put the first empirical evidence for the French stock market while most prior studies deal exclusively with the US stock market. Notably, we find significant effects of firm's investor following on volatility even after controlling for market's investor following. Most importantly, to the extent that online search is more likely emanating from less sophisticated investors, we suggest that retail investors behave as noise traders in the French stock market [Foucault et al. (2011)]. Last, but not least, we add to the volatility literature since the determinants of the stock market volatility are still under debate.

The remainder of this paper is organized as follows. In Section 2, we describe the data and report basic statistics. We present the empirical results and discuss their implications in Section 3. Further, we check the robustness of our findings to see how sensitive the empirical results are to the inclusion of the online search variables' effect. Section 4 concludes.

\section{DATA AND PRELIMINARY ANALYSIS}

\subsection{Online Search Behavior: A Novel Proxy Of Investor Following}

As mentioned in the introduction, we proxy investor following on the basis of investors' online search behavior provided by "Google Insights for Search". The online search traffic of a particular term is calculated as the number of searches for this term relative to the overall total number of Internet searches in Google at a particular point in time. To control for the increased use of the Internet over time, this ratio is then, normalized by the highest query share of that term over the time-series. Thus, Google data ranges from 0 to 100 with 100 representing the highest level of search traffic during the sample period. Lastly, the Google data is available on a daily, monthly and weekly frequency beginning in 2004.

To identify a firm's investor following in Google, we employ the firm name rather than the stock ticker. Actually, we use the two alternatives but the latter tend to be unproductive for most of the stocks in our sample. In addition to a proxy of firm's investor following, we construct a proxy for market's investor following on the basis of online search of the term "CAC 40 ". Finally, note that we filter the data by country so that only queries submitted within France are defined. 


\subsection{Sample Construction}

Our data set ranges from January 2004 to June 2012 to match the Google data. Alternately, we first start by the 40 stocks which constitute the CAC 40 index as of January 2004. Then, for every stock in our sample, we manually download the corresponding online search data. Finally, after some restrictions ${ }^{1}$, we have a final sample which consists of 30 out of the 40 initial stocks. Appendix A presents a list of the stocks in our sample along with the corresponding search queries we finally adopted.

Given our sample period, Google data is only available on a weekly frequency. Thus, we use weekly data instead of daily data in the regression analysis. Furthermore, this allows us somehow to reduce any potential biases that may arise, such as non-synchronous trading days.

\subsection{Basic Statistics}

Before starting the empirical analysis, it is worth assessing the behavior of the data. In the first step, we run statistical tests of the Google data under analysis. The Jarque-Bera (J-B) statistical test calculates the skewness and kurtosis of the series. The null hypothesis is in favor of a normal distribution. As shown in Table 1, the online search variables are not normally distributed displaying positive skewness and excess kurtosis for the majority of stocks at the level $1 \%$. Accordingly, the Google data used hereafter are logarithmically transformed.

\footnotetext{
${ }^{1}$ To guarantee unbiased results, we exclude from our sample stocks such as "Thales" and "TF1" because they have some other meanings in France.
} 
Table 1. Descriptive Statistics Of Google Data

This table reports the descriptive statistics of the original information demand data (GSV). GSV is the firm name search intensity defined as the weekly search volume index of a firm name on Google, scaled from 0 to 100 by Google Insights for search. The sample spans from January 2004 to June 2012. This table reports also the central tendency characteristics (Mean and Median), the kurtosis, the skewness; in addition to the standard deviation (dispersion characteristics) and the coefficient of variation (CV). Lastly, J-B is the Jarque-Bera test for normality based on skewness and excess kurtosis.

\begin{tabular}{|c|c|c|c|c|c|c|c|}
\hline Stock & Mean & Median & St.Dev & CV & Skew. & Kurt. & J-B \\
\hline Accor & 43,3589 & 40 & 14,9365 & 0,3444 & 0,8139 & 3,1109 & $40,07 * * *$ \\
\hline Axa & 73,9548 & 74 & 6,8479 & 0,0925 & 0,1989 & 3,1170 & $143,42 * * *$ \\
\hline Air Liquide & 36,7652 & 33 & 12,4620 & 0,3389 & 1,5934 & 6,2081 & 3,39 \\
\hline Arcelor & 15,1467 & 14 & 8,8667 & 0,5853 & 3,3686 & 25,3191 & $367,19 * * *$ \\
\hline Bnp Paribas & 38,8532 & 38 & 15,6388 & 0,4025 & 1,0644 & 4,4970 & $77,32 * * *$ \\
\hline Bouygues & 44,2708 & 42 & 9,7337 & 0,2198 & 1,0666 & 5,5091 & $90,84 * * *$ \\
\hline Cap Gemini & 22,3115 & 16 & 17,8874 & 0,8017 & 1,7121 & 6,2650 & $153,86 * * *$ \\
\hline Carrefour & 63,2347 & 61 & 11,0266 & 0,1743 & 0,6705 & 3,4319 & $31,81 * * *$ \\
\hline Crédit Agricole & 64,3972 & 67 & 13,0746 & 0,2030 & $-0,57921$ & 2,5968 & $22,07 * * *$ \\
\hline Danone & 33,2054 & 27 & 19,0002 & 0,5722 & 1,1781 & 1,1781 & $75,65 * * *$ \\
\hline Dexia & 15,3860 & 14 & 7,0004 & 0,4549 & 8,2089 & 89,0125 & $670,36 * * *$ \\
\hline Eads & 37,4763 & 31 & 16,3717 & 0,4368 & 1,0588 & 3,5529 & $64,12 * * *$ \\
\hline France Telecom & 32,2347 & 26 & 24,1480 & 0,7491 & 0,6517 & 2,1488 & $70,47 * * *$ \\
\hline Lafarge & 43,2031 & 40 & 13,7878 & 0,3191 & 0,8103 & 3,1042 & $32.09 * * *$ \\
\hline Lagardère & 13,1286 & 11 & 8,7875 & 0,6693 & 4,9021 & 41,9290 & $485,05^{* * *}$ \\
\hline L’oréal & 27,4424 & 22 & 18,1123 & 0,6600 & 0,9967 & 3,8601 & $62,88 * * *$ \\
\hline LVMH & 35,5349 & 33 & 12,8964 & 0,3629 & 1,1285 & 4,5981 & $84,10 * * *$ \\
\hline Michelin & 62,0654 & 60 & 12,7661 & 0,2056 & 0,6662 & 3,3263 & $30,43 * * *$ \\
\hline Pernod Ricard & 23,5553 & 20 & 13,1578 & 0,5585 & 1,5021 & 7,6871 & $150,74 * * *$ \\
\hline Peugeot & 62,8465 & 61 & 9,0052 & 0,1432 & 0,8285 & 3,6971 & $47,05 * * *$ \\
\hline PPR & 31,4379 & 27 & 13,6110 & 0,4329 & 1,60987 & 6,5334 & $148,34 * * *$ \\
\hline Renault & 55,4921 & 54 & 9,5813 & 0,1726 & 0,7588 & 3,6742 & $41,31 * * *$ \\
\hline Saint Gobain & 41,1535 & 39 & 12,9640 & 0,3150 & 1,0544 & 4,5849 & $77,70 * * *$ \\
\hline Sanofi & 21,6298 & 20 & 8,4790 & 0,3920 & 2,7711 & 21,6114 & $317,35 * * *$ \\
\hline Schneider & 46,5237 & 43 & 14,8258 & 0,3186 & 0,5453 & 2,8807 & $20,20 * * *$ \\
\hline Société Générale & 49,7449 & 52 & 14,4687 & 0,2908 & 0,1855 & 3,3176 & 4,50 \\
\hline STMIcroelectronics & 21,3476 & 17 & 16,0484 & 0,7517 & 1,8315 & 6,9248 & $170,59 * * *$ \\
\hline Total & 55,1083 & 52 & 11,0926 & 0,2012 & 0,7746 & 3,3281 & $38,61 * * *$ \\
\hline Vinci & 6,1986 & 5 & 5,5336 & 0,8927 & 12,3465 & 195,6525 & $840,43 * * *$ \\
\hline Vivendi & 22,60948 & 16 & 15,44113 & 0,6829 & 1,988646 & 7,550328 & $189,22 * * *$ \\
\hline CAC 40 & 11,03612 & 9 & 8,753205 & 0,7931 & 6,104132 & 54,80927 & $558,49 * * *$ \\
\hline
\end{tabular}

$*, * *, * * *$ denote $10 \%, 5 \%$ and $1 \%$ significance levels.

Table 2 reports the unit root tests (Augmented Dickey Fuller (ADF) and Phillips-Perron (PP) tests) of the Google data. The null hypothesis in both tests is the presence of a unit root. As can be seen in Table 2, for all the stocks in our sample, the time series are stationary around a deterministic trend at the $99 \%$ significance level. 
Table 2. Unit Root Tests On Google Data

This table reports the results of two unit root tests of Google search volume: the Augmented Dickey-Fuller test (ADF, Dickey and Fuller (1979)) and the Phillips-Perron test (PP, Phillips and Perron (1988)). GSV is the firm name online search frequency, scaled from 0 to 100 by Google Insights for search. In both tests, the null hypothesis is the existence of a unit root (stationarity).

The sample period spans from January 2004 to June 2012.

\begin{tabular}{|c|c|c|}
\hline Stock & ADF & $\mathbf{P P}$ \\
\hline Accor & $-8,392 * * *$ & $-8,296 * * *$ \\
\hline Air Liquide & $-12,454 * * *$ & $-13,210 * * *$ \\
\hline Axa & $-10,545^{* * *}$ & $-10,626 * * *$ \\
\hline Arcelor Mittal & $-8,370 * * *$ & $-8,219 * * *$ \\
\hline Bnp Paribas & $-4,303 * * *$ & $-3,999 * * *$ \\
\hline Bouygues & $-9,071 * * *$ & $-9,069 * * *$ \\
\hline Cap Gemini & $-9,273 * * *$ & $-8,948 * * *$ \\
\hline Carrefour & $-7,227 * * *$ & $-7,262 * * *$ \\
\hline Crédit Agricole & $-4,258 * * *$ & $-3,381 * *$ \\
\hline Danone & $-9,260 * * *$ & $-9,034 * * *$ \\
\hline Dexia & $-11,558 * * *$ & $-11,632 * * *$ \\
\hline EADS & $-10,546 * * *$ & $-10,580 * * *$ \\
\hline France Télécom & $-6,373 * * *$ & $-5,661 * * *$ \\
\hline Lafarge & $-15,391 * * *$ & $-16,334 * * *$ \\
\hline Lagardère & $-10,639 * * *$ & $-10,485 * * *$ \\
\hline L'oréal & $-8,689 * * *$ & $-8,543 * * *$ \\
\hline LVMH & $-9,560 * * *$ & $-9,457 * * *$ \\
\hline Michelin & $-3,262 * * *$ & $-4,114 * * *$ \\
\hline Pernod Ricard & $-10,720 * * *$ & $-10,792 * * *$ \\
\hline Peugeot & $-7,444 * * *$ & $-7,498 * * *$ \\
\hline PPR & $-13,178 * * *$ & $-13,597 * * *$ \\
\hline Renault & $-8,205 * * *$ & $-8,260 * * *$ \\
\hline Saint Gobain & $-12,324 * * *$ & $-12,493 * * *$ \\
\hline Sanofi & $-11,811 * * *$ & $-12,031 * * *$ \\
\hline Schneider & $-8,215^{* * *}$ & $-7,805 * * *$ \\
\hline Société Générale & $-4,900 * * *$ & $-4,112 * * *$ \\
\hline STMIcroelectronics & $-8,542 * * *$ & $-7,357 * * *$ \\
\hline Total & $-9,091 * * *$ & $-9,026 * * *$ \\
\hline Vinci & $-15,846^{* * *}$ & $-16,466^{* * *}$ \\
\hline Vivendi & $-9,123 * * *$ & $-8,907 * * *$ \\
\hline CAC 40 & $-6,270 * * *$ & $-6,320 * * *$ \\
\hline
\end{tabular}

In the next step, we apply once again the ADF and PP unit root tests to control for the stationarity of the weekly return series. Table 3 shows that; for all the stocks of the chosen firms, returns are stationary at the $99 \%$ significance level. 
Table 3. Unit Root Tests On The Weekly Return Series

This table reports the results of two unit root tests on the stock returns series: the Augmented Dickey-Fuller test (ADF, Dickey and Fuller (1979)) and the Phillips-Perron test (PP, Phillips and Perron (1988)). The null hypothesis in both tests is the presence of a unit root.

The sample period spans from January 2004 to June 2012.

\begin{tabular}{|c|c|c|}
\hline 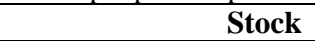 & ADF & PP \\
\hline Accor & $-21,513 * * *$ & $-21,530 * * *$ \\
\hline Air liquide & $-23,813 * * *$ & $-24,545 * * *$ \\
\hline Arcelor Mittal & $-21,784 * * *$ & $-21,609 * * *$ \\
\hline Axa & $-21,244 * * *$ & $-21,260 * * *$ \\
\hline Bnp Paribas & $-24,832 * * *$ & $-24,729 * * *$ \\
\hline Bouygues & $-23,866^{* * *}$ & $-23,777 * * *$ \\
\hline Cap Gemini & $-21,847 * * *$ & $-21,884 * * *$ \\
\hline Carrefour & $-22,649 * * *$ & $-22,694 * * *$ \\
\hline Crédit Agricole & $-21,807 * * *$ & $-21,729 * * *$ \\
\hline Danone & $-25,670 * * *$ & $-25,686 * * *$ \\
\hline Dexia & $-18,380 * * *$ & $-18,460 * * *$ \\
\hline Eads & $-22,659 * * *$ & $-22,710 * * *$ \\
\hline France Telecom & $-26,434 * * *$ & $-26,515 * * *$ \\
\hline Lafarge & $-20,627 * * *$ & $-20,638 * * *$ \\
\hline Lagardère & $-22,988 * * *$ & $-22,972 * * *$ \\
\hline L'oréal & $-22,294 * * *$ & $-22,294 * * *$ \\
\hline LVMH & $-22,462 * * *$ & $-22,582 * * *$ \\
\hline Michelin & $-22,658 * * *$ & $-22,658 * * *$ \\
\hline Pernod Ricard & $-24,759 * * *$ & $-24,919 * * *$ \\
\hline Peugeot & $-21,387 * * *$ & $-21,296 * * *$ \\
\hline PPR & $-21,701 * * *$ & $-21,760 * * *$ \\
\hline Renault & $-19,427 * * *$ & $-19,595 * * *$ \\
\hline Saint Gobain & $-21,292 * * *$ & $-21,331 * * *$ \\
\hline Sanofi & $-26,383 * * *$ & $-26,879 * * *$ \\
\hline Schneider & $-24,123 * * *$ & $-24,274 * * *$ \\
\hline Société Générale & $-23,658 * * *$ & $-23,485 * * *$ \\
\hline STMIcroelectronics & $-19,980 * * *$ & $-20,149 * * *$ \\
\hline Total & $-23,806 * * *$ & $-24,109 * * *$ \\
\hline Vinci & $-24,011 * * *$ & $-23,828 * * *$ \\
\hline Vivendi & $-24,317 * * *$ & $-24,352 * * *$ \\
\hline CAC 40 & $-24,194 * * *$ & $-24,192 * * *$ \\
\hline
\end{tabular}

Then, before undertaking an estimation of the conditional volatility, we analyze the behavior of the return series. First, we assess whether the stock returns have an autoregressive conditional heteroskedastic structure (ARCH effect). Thus, we use the Lagrange multiplier (LM) test, whose null hypothesis is the existence of homoskedastic variances. We also check the presence of autocorrelation of the stock returns by applying the LjungeBox test which the null hypothesis is no autocorrelation. 
Table 4. Statistical Tests On The Weekly Return Series

This table reports the descriptive statistics of the logarithmic stock returns. The sample spans from January 2004 to June 2012 . This table reports not only the central tendency characteristics (Mean and Median), the kurtosis and the skewness; but also the standard deviation (dispersion characteristics) of returns. J-B is the Jarque-Bera $(\mathrm{J}-\mathrm{B})$ normality test statistic estimated on the basis of the skewness and excess kurtosis. $\mathrm{LM}(6)$ refers to the Lagrange multiplier test for autoregressive conditional heteroskedasticity and more precisely the ARCH effects of order 6. Q(6) are the Portmanteau tests for white noise of order 6 for the returns.

\begin{tabular}{|c|c|c|c|c|c|c|c|c|}
\hline Stock & Mean & Median & St,Dev & Skew, & Kurt, & LM(6) & $Q(6)$ & J-B \\
\hline Accor & 0,0001 & 0,0038 & 0,0468 & $-0,3809$ & 4,8058 & $62,484 * * *$ & 7,2279 & $70,9066 * * *$ \\
\hline Axa & $-0,0011$ & 0,0016 & 0,0612 & $-0,5405$ & 8,2865 & $61,872 * * *$ & 6,9682 & $537,4461 * * *$ \\
\hline Air Liquide & 0,0016 & 0,0023 & 0,0301 & $-0,4994$ & 5,3775 & $98,786^{* * *}$ & $18,544 * * *$ & $122,7611 * * *$ \\
\hline Arcelor & 0,0014 & 0,0050 & 0,0717 & $-0,3688$ & 7,0288 & $52,819 * * *$ & 9,8926 & $309,6516^{* * *}$ \\
\hline Bnp Paribas & $-0,0010$ & 0,0009 & 0,0610 & $-0,3390$ & 11,0515 & $157,216 * * *$ & $22,8136 * * *$ & $1205,100 * * *$ \\
\hline Bouygues & $-0,0003$ & 0,0014 & 0,0468 & 0,1211 & 7,8222 & $64,983 * * *$ & $14,8725^{* *}$ & $430,3084 * * *$ \\
\hline Cap Gemini & $-0,0006$ & $-0,0010$ & 0,0517 & $-0,5811$ & 6,7921 & 1,715 & 3,6918 & $290,3745 * * *$ \\
\hline Carrefour & $-0,0020$ & $-0,0002$ & 0,0418 & $-0,8776$ & 8,9238 & $26,984 * * *$ & 6,7363 & $704,6170 * * *$ \\
\hline Crédit Agricole & $-0,0036$ & $-0,0008$ & 0,0635 & $-0,3082$ & 6,8227 & $84,293 * * *$ & 9,0385 & $276,7534 * * *$ \\
\hline Danone & 0,0010 & 0,0008 & 0,0318 & $-0,3346$ & 5,1565 & $16,142 * * *$ & $30,3888 * * *$ & $94,11286 * * *$ \\
\hline Dexia & $-0,0034$ & 0,0000 & 0,0464 & $-2,5037$ & 24,3462 & $145,683 * * *$ & $22,5754 * * *$ & $8873,633 * * *$ \\
\hline Eads & 0,0009 & 0,0017 & 0,0522 & $-0,4071$ & 6,8567 & $17,360 * * *$ & 7,1832 & $286,7945 * * *$ \\
\hline France Telecom & $-0,0017$ & 0,0000 & 0,0339 & $-0,0784$ & 7,3763 & $57,450 * * *$ & $24,0056^{* * *}$ & $353,9770 * * *$ \\
\hline Lafarge & $-0,0011$ & 0,0008 & 0,0512 & $-0,5769$ & 7,7565 & 79,93612 & $15,428 * *$ & $442,2045^{* * *}$ \\
\hline Lagardère & $-0,0016$ & 0,0008 & 0,0443 & $-0,6942$ & 7,5582 & $62,301 * * *$ & $10,7316^{*}$ & $419,1038 * * *$ \\
\hline L’oréal & 0,0008 & 0,0017 & 0,0304 & $-0,3334$ & 4,9502 & $29,240 * * *$ & 4,8640 & $78,41971 * * *$ \\
\hline LVMH & 0,0015 & 0,0017 & 0,0380 & $-0,2498$ & 5,7158 & $85,857 * * *$ & 8,8792 & $140,7580 * * *$ \\
\hline Michelin & 0,0008 & 0,0051 & 0,0509 & $-0,3695$ & 4,4287 & $33,674 * * *$ & 7,4867 & $47,76518 * * *$ \\
\hline Pernod Ricard & 0,0021 & 0,0033 & 0,0399 & $-0,7820$ & 13,8522 & $158,623^{* * *}$ & $17,4691 * * *$ & $2219,043 * * *$ \\
\hline Peugeot & $-0,0034$ & $-0,0035$ & 0,0562 & $-0,3781$ & 5,0756 & $89,082 * * *$ & $10,8649 *$ & $90,08503 * * *$ \\
\hline PPR & 0,0007 & 0,0033 & 0,0503 & $-0,2407$ & 9,2399 & $149,894 * * *$ & 8,4517 & $722,9974 * * *$ \\
\hline Renault & $-0,0012$ & 0,0002 & 0,0615 & $-0,8223$ & 8,1107 & $80,183 * * *$ & $12,4444 * *$ & $532,0599 * * *$ \\
\hline Saint Gobain & $-0,0004$ & 0,0007 & 0,0526 & $-0,5373$ & 8,3626 & $50,407 * * *$ & 5,0421 & $552,1382 * * *$ \\
\hline Sanofi & $9,2 \mathrm{E}-05$ & 0,0021 & 0,0362 & $-1,4330$ & 13,5594 & $94,015^{* * *}$ & $38,6758 * * *$ & $2209,759 * * *$ \\
\hline Schneider & 0,0012 & 0,0021 & 0,0464 & $-0,3368$ & 6,3417 & $65,928 * * *$ & 9,9681 & $214,5111 * * *$ \\
\hline Société Géné & $-0,0028$ & $-0,0006$ & 0,0689 & $-0,4540$ & 6,6876 & $83,699 * * *$ & 10,6282 & $266,2356 * * *$ \\
\hline STMIcroelectronics & $-0,0037$ & $-0,0041$ & 0,04973 & $-0,0816$ & 4,1773 & $35,048 * * *$ & $14,7491 * *$ & $26,07950 * * *$ \\
\hline Total & $4,6 \mathrm{E}-05$ & 0,0019 & 0,0346 & $-0,7057$ & 10,7258 & $80,068 * * *$ & $16,7653^{* * *}$ & $1138,514 * * *$ \\
\hline Vinci & 0,0018 & 0,0023 & 0,0423 & $-0,2784$ & 7,2684 & $31,964 * * *$ & $13,3334 * *$ & $342,0336 * * *$ \\
\hline Vivendi & $-0,0006$ & 0,0024 & 0,0355 & $-0,8434$ & 7,5717 & $14,902 * *$ & $11,5241 *$ & $438,3193 * * *$ \\
\hline CAC 40 & 0,0002 & 0,0023 & 0,0315 & $-0,9164$ & 9,6706 & $45,278^{* * *}$ & $15,7711 * *$ & $883,3629 * * *$ \\
\hline
\end{tabular}

According to the results reported in Table 4, the LM test at 6 lags confirms the presence of an ARCH effect in the return series with the exception of Cap Gemini and Lafarge. This evinces that the variance of the errors of the returns is not constant, but rather varies over time. This finding can be essentially attributed to the high volatility of financial markets and mainly over the last decades. Otherwise, the Portmanteau (Q) test at 6 lags rejects the hypothesis that there is no autocorrelation in the time series for 13 out of 40 stocks in our sample. Finally, the J-B test for normality rejects also the null hypothesis of normality of the returns for all the stocks in our sample.

Taken together, our results suggest that volatility can be estimated through a model of the ARCH family, firstly introduced by Engle (1982).Indeed, given the heteroskedasticity of the stock returns, these models are appropriate for financial series displaying non constant conditional variance over time. In our setting, we make use of the Generalized Autoregressive Conditional Heteroskedasticity model [GARCH (p,q)] to estimate the conditional volatility of the return series [Bollerslev (1986)]. Actually, GARCH (p,q) models are easy to estimate and, even in its simplest form, it has proven surprisingly successful in estimating conditional variances. Further, the GARCH model has the appeal of considering the evolving conditional volatility as well as the volatility clustering [Nikolaos et al. (2009)]. 


\section{EMPIRICAL ANALYSIS}

As previously introduced, we investigate whether investor following proxied by online search behavior is a determinant of the stock market volatility. Before undertaking the main empirical analysis, a natural starting point is to test the correlation between online search and volatility on the French stock market. Volatility is measured by the standard deviations of returns.

Table 5. Correlation Between Stock Volatility And Investors' Online Search

This table presents the Pearson correlation coefficients between stock unconditional volatility and online search variables. Unconditional volatility is proxied by the standard deviations of stock returns. While, stock-specific and market-related online information search are measured by Google search volume of the firm name and Google search volume of the term "CAC40", respectively.

\begin{tabular}{|c|c|c|}
\hline Stock & Stock-specific & Market-related \\
\hline Accor & $-0,3606 * * *$ & $0,6492 * * *$ \\
\hline Air liquide & $-0,1254 * * *$ & $0,5751 * * *$ \\
\hline Arcelor Mittal & $0,1049 * *$ & $0,5958 * * *$ \\
\hline Axa & $0,3792 * * *$ & $0,6821 * * *$ \\
\hline Bnp Paribas & $0,2434 * * *$ & $0,6017 * * *$ \\
\hline Bouygues & $0,1005^{* *}$ & $0,7122 * * *$ \\
\hline Cap Gemini & $-0,0588$ & $0,4949 * * *$ \\
\hline Carrefour & $0,1938 * * *$ & $0,6257 * * *$ \\
\hline Crédit Agricole & $-0,1210 * *$ & $0,6345^{* * *}$ \\
\hline Danone & $-0,1397 * * *$ & $0,5971 * * *$ \\
\hline Dexia & $0,3780 * * *$ & $0,6068 * * *$ \\
\hline Eads & $-0,0942 * *$ & $0,4267 * * *$ \\
\hline France Telecom & $-0,0793 *$ & $0,5045 * * *$ \\
\hline Lafarge & $-0,2930 * * *$ & $0,6453 * * *$ \\
\hline Lagardère & $-0,0277$ & $0,6478 * * *$ \\
\hline L'oréal & $-0,1715^{* * *}$ & $0,5957 * * *$ \\
\hline LVMH & $-0,2419 * * *$ & $0,6459 * * *$ \\
\hline Michelin & 0,0677 & $0,3804 * * *$ \\
\hline Pernod Ricard & 0,0547 & $0,7349 * * *$ \\
\hline Peugeot & $-0,3926 * * *$ & $0,5443 * * *$ \\
\hline PPR & $-0,2120 * * *$ & $0,6424 * * *$ \\
\hline Renault & $-0,3246 * * *$ & $0,6762 * * *$ \\
\hline Saint Gobain & $-0,1491 * * *$ & $0,6941 * * *$ \\
\hline Sanofi & 0,0452 & $0,5461 * * *$ \\
\hline Schneider & $-0,1747 * * *$ & $0,7203 * * *$ \\
\hline Société Générale & $-0,1282 * * *$ & $0,6356^{* * *}$ \\
\hline STMIcroelectronics & $-0,1671 * * *$ & $0,5204 * * *$ \\
\hline Total & $-0,1653 * * *$ & $0,7324 * * *$ \\
\hline Vinci & $-0,0777$ & $0,7353 * * *$ \\
\hline \multirow[t]{2}{*}{ Vivendi } & $-0,0959 * *$ & $0,6148 * * *$ \\
\hline & ce at the $10 \%, 5 \%$ & \\
\hline
\end{tabular}

The results reported in Table 5 show that firm's investor following and the stock volatility are negatively and significantly correlated in most cases (17 out of 30 cases) at the $95 \%$ significance level; while correlation is significant and positive in 7 cases at the $5 \%$ level. This evidence is even stronger for the market's investor following with all the correlation coefficients being significantly positive at the $99 \%$ significance level.

\subsection{Regression models}

As mentioned above, to model the conditional variance of the returns, we use the autoregressive model with generalized conditional heteroskedasticity $(\mathrm{GARCH})$. Since our primary interest lies on how investor following affects the conditional volatility of the French stocks, we augment the GARCH $(1,1)$ Market model with measures of investor following by allowing it to enter the specification of the conditional variance.

The model used in this study is illustrated in Equation (1). Note that the presence of heteroskedasticity in the series, as reported in Section 2.3, suggests that the GARCH specification is suitable for the analysis: 


$$
\begin{gathered}
r_{i, t}=\mu+\lambda R_{C A C 40}+\varepsilon_{t} / \varepsilon_{t} \sim N\left(0, \sigma_{t}^{2}\right)(1) \\
\sigma_{t}^{2}=\omega+\alpha \varepsilon_{t-1}^{2}+\beta \sigma_{t-1}^{2}+\delta \text { Ln }\left(\text { Online_Search }_{i, t}\right)+\theta \text { Ln }\left(\text { Online_Search }_{M, t}\right)
\end{gathered}
$$

Where, $r_{i, t}$ is the weekly stock return of the firm $i$ in week $t ; R_{C A C 40}$ is the market return ${ }^{2}$ at time $t$; and $\varepsilon_{t}$ is the stochastic error term of the regression, with the conditional variance $\sigma_{t}^{2}$ following a GARCH $(\mathrm{p}, \mathrm{q})$ model. P represents the number of lags of the conditional variance (ARCH effect); while q defines the number of lags of the squared innovations (GARCH effect). $\mu$ and $\mathrm{w}$ are constants.

Online search is a proxy of investor following. For each stock in our sample, firm's investor following $\left[\operatorname{Ln}\left(\right.\right.$ Online_Search $\left.\left.h_{i, t}\right)\right]$ is derived from the online search traffic of the firm name. Similarly, we proxy market's investor following $\left[\operatorname{Ln}\left(\right.\right.$ Online_Search $\left.\left._{M, t}\right)\right]$ on the basis of online search traffic for the term "CAC 40". As can be seen, interestingly, Google allows us to cleanly separate the effect of investor following at the firm and market level, respectively.

The ARCH parameters illustrate the reaction of the volatility, while the parameters associated with the GARCH component represent the persistence of the volatility, and in less technical words; the risk in the return series. In the GARCH model, volatility persistence is assessed by the sum of these two parameters. Thus, the sum of the $\mathrm{ARCH}$ and GARCH parameters defines whether the risk in the stock return series persists over time.

We are staying with a GARCH $(1,1)$ model. For instance, Hansen and Lunde (2005) find no other more sophisticated model can describe the conditional variance better than GARCH $(1,1)$. In our setting, the choice of the best model is taken not only on the basis of the statistical significance of the estimated coefficient, but the Akaike information criterion (AIC) and Bayesian information criterion (BIC) as well, always adopting models with low order. Note that the estimation of the models' coefficients is done by the conditional maximum likelihood method.

\subsection{GARCH estimation results}

Regression results are summarized in Table 6. At first, our results suggest that the GARCH $(1,1)$ market model is appropriate for each stock in our sample. Indeed, we believe that the choice of this specification is judicious, since the coefficient $\lambda$ and the ARCH and GARCH coefficients are significant, as well as the fact that the influence of investor following was well captured by the models.

${ }^{2}$ In this study, we use the CAC40 index as the benchmark for the overall French stock market. 
Table 6. Investor Following And Conditional Volatility

This table assesses the role of investor following as a determinant of the stock market volatility. Volatility is estimated via Maximum Likelihood with normally distributed errors of the extended GARCH Market Model after controlling for online search variables. For each stock in our sample, the estimated set of equations is:

$r_{t}=\mu+\lambda v_{t}+\varepsilon_{t} / \varepsilon_{t} \sim N\left(0, \sigma_{t}^{2}\right) ;$ For the conditional mean

$\sigma^{2}=\omega+\alpha \varepsilon_{t-1}^{2}+\beta \sigma_{t-1}^{2}+\delta O I S_{i, t}+\theta O O_{M, t} \quad ;$ For the conditional variance

$\mu$ is the constant; $\mathrm{r}_{\mathrm{t}}$ is the stock $\log$ return; $\delta$ and $\theta$ are the estimated coefficients for firm-specific online information search and market-related online information search, respectively and; $\lambda$ is the coefficient for market return. While, $\alpha$ and $\beta$ denote the ARCH and GARCH term coefficients, respectively. The sample spans from January 2004 to June 2012.LM(6) is the Lagrange multiplier test for conditional heteroskedasticity of order 6. Q(6) and $\mathrm{Q}^{2}(6)$ are the Portmanteau (Q) tests for white noise of order 6 for the standardized residuals and for the squared standardized residuals, respectively. J-B is the Jarque-Bera test for normality.The $\mathrm{AdjR}^{2}$ values assess if the independent variables that are added to the regression enhance the overall explanatory power of the regression. Robust standard errors are presented in parentheses under the coefficient estimates.

\begin{tabular}{|c|c|c|c|c|c|c|c|c|c|c|c|c|}
\hline Stock & $\omega$ & $a$ & $\beta$ & $\delta$ & $\theta$ & $\mu$ & $\Lambda$ & LM(6) & $Q(6)$ & $Q^{2}(6)$ & J-B & Adj. $\mathbf{R}^{2}$ \\
\hline \multirow[t]{2}{*}{ Accor } & $-0,0007 * *$ & & $0,8210 * * *$ & & $0,0003 * * *$ & & $1,0723 * * *$ & 1,1840 & 3,3347 & 1,1910 & $20,7695 * * *$ & 0,5493 \\
\hline & $(0,0003)$ & & $(0,062362)$ & & $(0,0001)$ & & $(0,0505)$ & & & & & \\
\hline \multirow{2}{*}{ Air liquide } & & $0,0892 * * *$ & $0,8477 * * *$ & & & $0,0013^{*}$ & $0,7857 * * *$ & 10,5689 & 6,9883 & $11,396 * *$ & $12,7064 * * *$ & 0,6223 \\
\hline & & $(0,0319)$ & $(0,0427)$ & & & $(0,0007)$ & $(0,0275)$ & & & & & \\
\hline \multirow{2}{*}{ Arcelor Mittal } & $-0,0014 * *$ & 0,2910 *** & $0,4278 * * *$ & $0,0006^{* * *}$ & & & $1,4880 * * *$ & 2,8033 & 5,3317 & 2,9482 & $25,3553 * * *$ & 0,4626 \\
\hline & $(0,0007)$ & $(0,0506)$ & $(0,1154)$ & $(0,0002)$ & & & $(0,0663)$ & & & & & \\
\hline \multirow{2}{*}{ Axa } & $0,0001 * * *$ & $0,0656^{* * *}$ & $0,7788^{* * *}$ & $-0,0001 * * *$ & $0,0002 * * *$ & & $1,5762 * * *$ & 2,4195 & 6,6595 & 2,7918 & $109,3163 * * *$ & 0,7283 \\
\hline & $(1,81 \mathrm{E}-05)$ & $(0,0305)$ & $(0,0372)$ & $(6,75 \mathrm{E}-06)$ & $(3,08 \mathrm{E}-05)$ & & $(0,0423)$ & & & & & \\
\hline \multirow{2}{*}{ Bnp Paribas } & $-0,0002 * *$ & $0,1174 * * *$ & $0,8392 * * *$ & & $5,36 \mathrm{E}-05^{* *}$ & & $1,2723 * * *$ & 5,6925 & 4,9433 & 5,6909 & $181,6979 * * *$ & 0,5559 \\
\hline & $(4,91 \mathrm{E}-05)$ & $(0,0351)$ & $(0,0391)$ & & $(3,02 \mathrm{E}-05)$ & & $(0,0413)$ & & & & & \\
\hline \multirow{2}{*}{ Bouygues } & & $0,0954 * *$ & $0,6293 * * *$ & $-0,0002 * * *$ & $0,0003 * * *$ & & 1,1160 *** & 4,4946 & 8,1276 & 4,5158 & 18,7856 **** & 0,5394 \\
\hline & & $(0,0420)$ & $(0,0908)$ & $7,55 \mathrm{E}-05$ & $(7,92 \mathrm{E}-05)$ & & $(0,0408)$ & & & & & \\
\hline \multirow{2}{*}{ Cap Gemini } & & & $0,8904 * * *$ & & & & $1,1040 * * *$ & 3,7527 & 6,2550 & 3,6315 & $12,5039 * * *$ & 0,4552 \\
\hline & & & $(0,0671)$ & & & & $(0,0486)$ & & & & & \\
\hline \multirow{2}{*}{ Carrefour } & & & $0,6741 * * *$ & & $0,0002 * *$ & & $0,8866 * * *$ & 7,6590 & $12,376^{* *}$ & 8,4511 & $159,9640^{* * * *}$ & 0,4775 \\
\hline & & & $(0,1723)$ & & $(0,0001)$ & & $(0,0480)$ & & & & & \\
\hline \multirow{2}{*}{ Crédit Agricole } & $0,0003^{* * *}$ & $0,0590 * * *$ & $0,8952 * * *$ & & $9,08 \mathrm{E}-05^{* * *}$ & $-0,0030 * *$ & $1,4365 * * *$ & 1,0613 & 5,2610 & 1,0130 & $21,0186^{* * * *}$ & 0,5686 \\
\hline & $(0,0001)$ & $(0,0198)$ & $(0,0298)$ & & $(3,03 \mathrm{E}-05)$ & $(0,0014)$ & $(0,0674)$ & & & & & \\
\hline \multirow{2}{*}{ Danone } & $0,0002 *$ & $0,0893^{* * * *}$ & $0,8076^{* * *}$ & $-5,30 \mathrm{E}-05 * * *$ & & & $0,6406 * * *$ & 3,1341 & 7,7354 & 2,8124 & $165,9029 * * *$ & 0,3836 \\
\hline & $(0,0001)$ & $(0,0272)$ & $(0,0582)$ & $(1,89 \mathrm{E}-05)$ & & & $(0,0445)$ & & & & & \\
\hline \multirow{2}{*}{ Dexia } & $0,0005 * * *$ & 0,1661 *** & $0,6000^{* * *}$ & $-0,0001 * * *$ & $-6,15 \mathrm{E}-05 * * *$ & & $0,5829 * * *$ & 1,1100 & 8,9806 & 1,1370 & 237,0385 *** & 0,1436 \\
\hline & $(4,23 \mathrm{E}-05)$ & $(0,0169)$ & $(0,0197)$ & $(1,95 \mathrm{E}-05)$ & $(1,88 \mathrm{E}-05)$ & & $(0,0313)$ & & & & & \\
\hline \multirow{2}{*}{ Eads } & $-0,0056^{* * *}$ & & $-0,3250 *$ & $0,0012 * * *$ & $0,0015 * * *$ & & $1,0542 * * *$ & 2,7960 & 4,5612 & 2,8960 & $159,2776^{* * * *}$ & 0,3992 \\
\hline & $(0,0008)$ & & $(0,1873)$ & $(0,0001)$ & $(0,0001)$ & & $(0,0661)$ & & & & & \\
\hline
\end{tabular}


Table 6 continued

\begin{tabular}{|c|c|c|c|c|c|c|c|c|c|c|c|c|}
\hline Stock & $\omega$ & $\alpha$ & $\beta$ & $\delta$ & $\theta$ & $\mu$ & $\Gamma$ & $\mathbf{L M}(6)$ & $Q(6)$ & $Q^{2}(6)$ & J-B & Adj. $\mathbf{R}^{2}$ \\
\hline \multirow{2}{*}{ France Télécom } & $-0,0002 * * *$ & $0,0259 * *$ & $0,9074 * * *$ & $3,34 \mathrm{E}-05^{*} * *$ & $7,67 \mathrm{E}-05^{* * * *}$ & $-0,0021^{*}$ & $0,6663 * * *$ & 3,275859 & 8,6310 & 3,2852 & $210,6759 * * *$ & 0,3285 \\
\hline & $(7,64 \mathrm{E}-05)$ & $(0,0129)$ & $(0,0389)$ & $(1,15 \mathrm{E}-05)$ & $(2,73 \mathrm{E}-05)$ & $(0,0012)$ & $(0,0461)$ & & & & & \\
\hline \multirow{2}{*}{ Lafarge } & & $0,0465 * *$ & 0,8590 *** & $-7,26 \mathrm{E}-05^{* * *}$ & & & $1,2177 * * *$ & 3,919534 & 7,1420 & 4,1151 & 367,0556 *** & 0,6514 \\
\hline & & $(0,0220)$ & $(0,0691)$ & $(4,22 \mathrm{E}-05)$ & & & $(0,0468)$ & & & & & \\
\hline \multirow{2}{*}{ Lagardère } & $-0,0002 * * *$ & & $0,8742 * * *$ & & $0,0001 * * *$ & & $0,9932 * * *$ & 1,025491 & 8,0384 & 1,0729 & $326,4199 * * *$ & 0,5046 \\
\hline & $\begin{array}{c}(5,77 \mathrm{E}-05) \\
\end{array}$ & & $(0,0386)$ & & $(4,32 \mathrm{E}-05)$ & & $(0,0514)$ & & & & & \\
\hline \multirow{2}{*}{ L'oréal } & & & $0,4711^{*}$ & & $0,0002 * * *$ & & $0,6614 * * *$ & 1,883101 & $12,438 * *$ & 2,1092 & $60,3657 * * *$ & 0,4141 \\
\hline & & & $(0,2660)$ & & $(0,0001)$ & & $(0,0407)$ & & & & & \\
\hline \multirow{2}{*}{ LVMH } & $-0,0007 * * *$ & & $0,4437 * * *$ & $0,0001^{*}$ & $0,0002 * * *$ & & 1,0049 *** & 3,103606 & 7,6921 & 3,1669 & $42,1161 * * *$ & 0,6241 \\
\hline & $(0,0002)$ & & $(0,1005)$ & $(6,11 \mathrm{E}-05)$ & $(4,59 \mathrm{E}-05)$ & & $(0,0325)$ & & & & & \\
\hline \multirow{2}{*}{ Michelin } & $-0,0033 * * *$ & & & $0,0007 * *$ & $0,0007 * * *$ & & $1,1554 * * *$ & 10,63297 & $15,822 * *$ & $10,961 *$ & $96,0143 * * *$ & 0,4797 \\
\hline & $(0,0012)$ & & & $(0,0003)$ & $(0,0001)$ & & $(0,0515)$ & & & & & \\
\hline \multirow{2}{*}{ Pernod Ricard } & & $0,1046 * * *$ & $0,8018^{* * * *}$ & & & $0,0023^{*}$ & $0,6510 * * *$ & 9,313102 & 6,4231 & 8,2174 & $84,7974 * * *$ & 0,4047 \\
\hline & & $(0,0277)$ & $(0,0493)$ & & & $(0,0012)$ & $(0,0408)$ & & & & & \\
\hline \multirow{2}{*}{ Peugeot } & & & $0,9621 * * *$ & & $0,0001 * *$ & $-0,0026 * *$ & $1,2224 * * *$ & 5,769627 & 8,7527 & 4,9286 & $4,1718^{* * *}$ & 0,5049 \\
\hline & & & $(0,0159)$ & & $(3,38 \mathrm{E}-05)$ & $(0,0015)$ & $(0,0622)$ & & & & & \\
\hline \multirow[b]{2}{*}{ PPR } & & $0,1595 * * *$ & $0,7004 * * *$ & & $0,0002 * *$ & & $0,9059 * * *$ & 1,273321 & 4,5408 & 1,3632 & $18,3853 * * *$ & 0,4914 \\
\hline & & $(0,0466)$ & $(0,0980)$ & & $(7,30 \mathrm{E}-05)$ & & $(0,0524)$ & & & & & \\
\hline \multirow{2}{*}{ Renault } & & $0,0580 * * *$ & $0,8740 * * *$ & & & & $1,4587 * * *$ & 4,504048 & 3,6629 & 4,7116 & $14,7316^{* * * *}$ & 0,6455 \\
\hline & & $(0,0221)$ & $(0,0413)$ & & & & $(0,0609)$ & & & & & \\
\hline \multirow{2}{*}{ Saint Gobain } & $-0,0004 * * *$ & $0,0676^{* * *}$ & $0,8453 * * *$ & $5,99 \mathrm{E}-05^{* * *}$ & $0,0001 * * *$ & & $1,2965^{* * *}$ & 1,743099 & 4,1046 & 1,6835 & $30,6541 * * *$ & 0,7086 \\
\hline & $\begin{array}{c}(1,76 \mathrm{E}-05) \\
\end{array}$ & $(0,0224)$ & $(0,0348)$ & $(2,12 \mathrm{E}-06)$ & $(1,73 \mathrm{E}-05)$ & & $(0,0374)$ & & & & & \\
\hline \multirow{2}{*}{ Sanofi } & & $0,0678^{* * * *}$ & $0,8975 * * *$ & & & & $0,6558 * * *$ & 2,569288 & 3,0004 & 2,3343 & $133,9879^{* * *}$ & 0,4105 \\
\hline & & $(0,0166)$ & $(0,0185)$ & & & & $(0,0371)$ & & & & & \\
\hline \multirow{2}{*}{ Schneider } & & & $0,9082 * * *$ & & & & $1,1821 * * *$ & 2,540438 & $16,402 * * *$ & 2,6625 & 5,4083* & 0,6649 \\
\hline & & & $(0,0722)$ & & & & $(0,0485)$ & & & & & \\
\hline \multirow{2}{*}{ Société Générale } & & $0,1039 * * *$ & $0,8321 * * *$ & & $0,0001 * * *$ & & $1,5202 * * * *$ & 4,413363 & $13,287 * *$ & 4,3422 & $54,4514 * * *$ & 0,6115 \\
\hline & & $(0,0238)$ & $(0,0299)$ & & $(2,95 \mathrm{E}-05)$ & & $(0,0587)$ & & & & & \\
\hline \multirow{2}{*}{ STMIcroelectronics } & $-0,0005^{*}$ & & $0,5046^{*}$ & & $0,0005^{* *}$ & $-0,0050 * * *$ & $1,1044 * * *$ & 1,094751 & 6,6197 & 1,0922 & $6,8837 * *$ & 0,4101 \\
\hline & $(0,0002)$ & & $(0,3016)$ & & $(0,0002)$ & $(0,0017)$ & $(0,0543)$ & & & & & \\
\hline \multirow{2}{*}{ Total } & & $0,0800 * * *$ & $0,8501 * * *$ & & & & $0,8763 * * *$ & $15,61069 * *$ & 6,7270 & $14,241 * *$ & $27,9319 * * *$ & 0,6631 \\
\hline & & $(0,0282)$ & $(0,0562)$ & & & & $(0,0323)$ & & & & & \\
\hline \multirow{2}{*}{ Vinci } & & $0,0298 * * *$ & $0,9575 * * *$ & $1,72 \mathrm{E}-05^{*}$ & & & $1,0871^{* * * *}$ & 8,171485 & 7,3192 & 9,1411 & $90,8086^{* * *}$ & 0,6466 \\
\hline & & $(0,0113)$ & $(0,0143)$ & $(1,01 \mathrm{E}-05)$ & & & $(0,0341)$ & & & & & \\
\hline \multirow{2}{*}{ Vivendi } & $-0,0008 * * *$ & $0,1463 * *$ & & $0,0002 * * *$ & $0,0003 * * *$ & & $0,8295 * * *$ & 2,432822 & 1,8229 & 2,4099 & $241,3342 * * *$ & 0,5250 \\
\hline & $(0,0003)$ & $(0,0657)$ & & $(8,43 \mathrm{E}-05)$ & $(5,11 \mathrm{E}-05)$ & & $(0,0367)$ & & & & & \\
\hline
\end{tabular}


Specifically, for all the stocks in our sample, the GARCH models were able to neutralize the effect of the conditional variance. The LM test (to control for conditional heteroskedasticity) did not reject the null hypothesis of absence of heteroskedasticity of the residuals and the Ljunge-Box test (Q test) reports there is no autocorrelation of the standardized residuals as well as the squared residuals.

However, the GARCH models are still unable to correct the excess kurtosis of the distributions, despite the huge reduction of values of the J-B test relative to the preliminary analysis of the return series. According to the J-B test for normality of the standardized residuals, the null hypothesis of normality of the residuals is rejected, keeping the leptokurtic distribution feature of the residuals.

The estimates of the ARCH and GARCH parameters are positive and their sum is less than 1, suggesting stationarity of the covariance. Most of the stocks have low ARCH effects (below 0.2) and high GARCH effects (greater than 0.6 ). Thus, in our setting, the conditional volatility does not vary suddenly, but rather tends to persist for long periods of time.

Lastly, the coefficient of determination of the regression (Adj. $\mathrm{R}^{2}$ ) ranges between 14, $36 \%$ and 72, 83\% suggesting good fit of the models.

As expected from correlation analysis presented in Table 5, the GARCH estimation results confirm that investor following has a significant effect on the volatility for stocks listed in the CAC 40. Intuitively, if investor online search result in retail trading, this would incorporate noise on stock prices which may in turn result in variations in the volatility of stock returns.

As can be seen in Table 6, we find that in most cases either firm-specific or market-related online information search is significant at the $95 \%$ significance level. Firm's investor following is a significant regressor in 13 cases, whereas market's investor following is significant for 19 out of the 30 stocks in our sample. The magnitude of estimated coefficients suggests that the effect of the two variables is comparable. Whereas, while all coefficients related to market's investor following are positive, the signs of firm's investor following remain mixed.

Taken together, our results suggest that investor following of market-related information has a significant positive association with conditional volatility. While, investor following of firm-specific information is also significant, but still has a lesser effect. Accordingly, the stock conditional volatility is more sensitive to investor following of market-related information. This confirms that investors are more likely to process more market news than firm-specific news [Peng and Xiong(2006)].

As a primary inference, we attribute these findings to a higher market-wide uncertainty leading to excessive transactions. Further, the online search effect on the stock volatility can partially be explained by shifts in investor overconfidence [(Kita et Wang (2012)].

In financial markets, searching activity (information-based trading) is a two edged sword in the sense that more search equals better information and closer matches between firm's information supply and investor interest on the one hand, while increasing investor confusion on the other hand. Thus, we cannot identify clearly even searching activity for firm-specific information is actually resolving information asymmetry or increasing uncertainty; which may partially explain our mixed results.

\subsection{Robustness Check}

In Table 5 and Table 6, we find strong evidence that investor following, proxied by online search behavior, is linked to the stock conditional volatility. In this section, we turn our attention from conditional to unconditional volatility and make use of the standard deviations of returns as an alternative measure of the stock volatility. More precisely, we regress, for each stock in our sample, the standard deviations of returns by online search variables, as 
previously defined, while controlling for other known determinants of volatility ${ }^{3}$ (trading volume and stock return). Robustness check results are provided upon request from authors.

In sum, our findings confirm our central hypothesis that investor following is a priced source of volatility in most cases. Accordingly, our results do not depend on the way we measure volatility.

\section{CONCLUSION}

In this paper, we investigate whether changes in firm's investor following can influence volatility in the French stock market. By defining a novel proxy of investor following, we contribute to the emerging literature of the impact of information technology on financial markets.

Theoretically, we draw on both the extensive literature on volatility and the more recent literature on Google search volume to examine another channel through which investors affect stock volatility. Empirically, results reveal that investor following, proxied by online search traffic, seems to co-move with the conditional volatility as estimated from GARCH $(1,1)$. Building on this evidence, we argue that this effect is consistent with the fact that some retail investors behave as noise traders in securities markets. In support of this claim, we further control for the investor following's effect on volatility by using the standard deviations of returns as an alternative measure of volatility and find the same results.

Natural extensions of this paper include testing for the predictive power of Google search volume data over other settings in the French stock market. While our results would not necessarily generalize to other stock markets, which generally do not face the same interactions, they do suggest that when trying to understand the stock market dynamics (especially in crises times); it is worth to identify less conventional determinants of the stock market activity.

\section{AUTHOR INFORMATION}

Amal Aouadi, is a Researcher at CRCGM Université d'Auvergne, France. Her research works focus is on risk management and investor attention. Her articles are published in refereed journals such as Economic Modelling and Journal of Applied Business Research. Email: amal.aouedi@gmail.com

Mohamed Arouri is an Associate Researcher at EDHEC Business School, France. His research works focus is on risk management, energy finance and international portfolio choice. His most recent articles are published in refereed journals such as Journal of Macroeconomics, Journal of Banking \& Finance, Ecological Economics, World Development, and Journal of International Money \& Finance. Email: Mohamed.arouri@ gmail.com

Frederic Teulon is the head of a Research center (IPAG Research Lab). TEULON made a career as a professor at various universities in Paris. He now teaches at the IPAG Business School. His main research areas are macroeconomics and international finance. His most recent articles are published in refereed journals such as Economic Modelling, Journal of Applied Business Research, Economics Bulletin. E-mail: f.teulon@ipag.fr

\section{REFERENCES}

Bank, M., Larch, M. and Peter, G., (2011), "Google Search Volume and its Influence on Liquidity and Returns of German Stocks", Financial Markets and Portfolio Management, 25, 239-264.

Bollerslev, T., (1986), "Generalized autoregressive conditional heteroskedasticity", Journal of Econometrics, 31, 307-327.

Da, Z., Engelberg, J. and Gao, P., (2011), “In Search of Attention”, Journal of Finance, 5, 1461-1499.

Dickey, D.A., Fuller, W.A., (1979), "Distribution of the estimators for autoregressive time 459 series with a unit root",Journal of the American Statistical Association, 74, 427-431.

${ }^{3}$ Details of the model specifications are not reported here to save space but available upon request. 
Dimpfl, T., Jank, S., (2011), “Can internet search queries help to predict stock market volatility?”, CFR Working Papers 11-15, University of Cologne, Centre for Financial Research (CFR).

Ding, R. and Hou, W., (2011), "Retail Investor Attention and Stock Liquidity", Working Paper.Durham Business School, Mill Hill Lane, DH1 3LB, United Kingdom.

Engle RF. (1982), "Autoregressive conditional heteroskedasticity with estimates of the variance of U.K. inflation”.Econometrica 1982;50:987e1008.

Fink, J., Fink, K., Grullon, G. and Weston, J., (2010), "What drove the increase in idiosyncratic risk during the internet boom?" Journal of Financial and Quantitative Analysis, 45, 1253-1278.

Kita, A. and Wang, Q. (2012), "Investor Attention and FX Market Volatility", Working paper.

Hansen, P. R., and Lunde, A., (2005), "A Forecast Comparison of Volatility Models: Does Anything Beat a GARCH $(1,1)$ ?” Journal of Applied Econometrics, 20, 873-889.

Merton, R., (1987), “A Simple Model of Capital Market Equilibrium with Incomplete Information”, Journal of Finance, 42, 483-510.

Mondria, J., Wu, T. and Zhang, Y., (2010), “The Determinants of International Investment and Attention Allocation", Journal of International Economics, 82, 85-95.

Peng, L. and Xiong, W., (2006), "Investor attention, overconfidence and category learning", Journal of Financial Economics, 80, 563-602.

Phillips, P.C.B., and Perron, P., (1988), “Testing for a unit root in time series regression”, Biometrika, 75, 335-346.

Shiller, Robert J., 1981, "Do stock prices move too much to be justified by subsequent changes in dividends?" American Economic Review, 71, 421-436.

Foucault, T., Sraer, D. and Thesmar, D.J., (2011), “Individual Investors and Volatility”, Journal of Finance, 66, 1369-1406.

Vlastakis, N. and Markellos, R. N., (2012), "Information Demand and Stock Market Volatility”, Journal of Banking and Finance, 36, 1808-1821.

Wei, Steven X., and Zhang, C., (2006), “Why did individual stocks become more volatile?”,Journal of Business, 79, 259-291. 
APPENDIX A. LIST OF STOCKS IN THE SAMPLE AND GOOGLE SEARCH QUERIES

\begin{tabular}{|c|c|}
\hline Stock & Google searchquery \\
\hline Accor & "accor" \\
\hline Air Liquide & "air Liquide" \\
\hline Axa & "axa" \\
\hline Arcelor Mittal & "arcelormittal" \\
\hline Bnp Paribas & "bnpparibas" \\
\hline Bouygues & "bouygues" \\
\hline Cap Gemini & "cap Gemini" \\
\hline Carrefour & "carrefour" \\
\hline Crédit Agricole & "credit Agricole" \\
\hline Danone & "danone" \\
\hline Dexia & "dexia" \\
\hline EADS & "eads" \\
\hline France Télécom & "france télécom" \\
\hline Lafarge & "lafarge" \\
\hline Lagardère & "lagardère" \\
\hline L’oréal & "l'oréal" \\
\hline LVMH & "lvmh" \\
\hline Michelin & "michelin" \\
\hline Pernod Ricard & "pernod ricard" \\
\hline Peugeot & "peugeot" \\
\hline PPR & "ppr" \\
\hline Renault & "renault" \\
\hline Saint Gobain & "saint gobain" \\
\hline Sanofi & "sanofi" \\
\hline Scheneider & "schneider" \\
\hline Société Générale & "société générale" \\
\hline STMIcroelectronics & "stmicroelectronics" \\
\hline Total & "total" \\
\hline Vinci & "vinci" \\
\hline Vivendi & "vivendi" \\
\hline CAC 40 & "cac 40" \\
\hline
\end{tabular}




\section{NOTES}

